\title{
The Income Inequality Hypothesis Revisited: Assessing the Hypothesis Using Four Methodological Approaches
}

\author{
Nigel Kragten ${ }^{1}$ (D) Jesper Rözer ${ }^{1}$
}

Accepted: 26 February 2016/Published online: 4 March 2016

(C) The Author(s) 2016. This article is published with open access at Springerlink.com

\begin{abstract}
The income inequality hypothesis states that income inequality has a negative effect on individual's health, partially because it reduces social trust. This article aims to critically assess the income inequality hypothesis by comparing several analytical strategies, namely OLS regression, multilevel regression, fixed effects models and fixed effects models using pseudo panel data. To test the hypothesis, data from two studies conducted between 1981 and 2014 were combined: the World Values Survey and the European Values Study. Three frequently used measures of health were taken into account. In the OLS and multilevel models, income inequality was often associated with better health, whereas in the fixed effects and pseudo panel data, income inequality was associated with poorer health, suggesting that the unexpected results of the OLS and multilevel methods might be explained by unobserved confounders. Furthermore, in almost all of the models, social trust mediates the relationship between income inequality and health, showing the importance of this mechanism. Interestingly, the pseudo panel data offer the strongest support for the income inequality hypothesis, suggesting that better controlling for confounding factors and/or more carefully monitoring cohort effects, may result in a better understanding whether and how income inequality can be harmful for people's health.
\end{abstract}

Keywords Income inequality $\cdot$ Health $\cdot$ Social trust $\cdot$ Pseudo panels $\cdot$ Multilevel regression · Fixed effects model

Electronic supplementary material The online version of this article (doi:10.1007/s11205-016-1283-8) contains supplementary material, which is available to authorized users.

Nigel Kragten

n.kragten@uva.nl

1 Department of Sociology, University of Amsterdam, Nieuwe Achtergracht 166, Amsterdam, The Netherlands 


\section{Introduction}

With rising levels of income inequality within numerous developed and developing countries, there is a growing pool of literature seeking to better understand the implications of inequality on society. One particular issue that has received much attention is the relationship between income inequality and health. The income inequality hypothesis (IIH) states that high income inequality is detrimental to human health, in particular because it has negative psychosocial effects (Gold et al. 2002; Pickett and Wilkinson 2015; Wilkinson 1996) and reduces social trust (Elgar 2010; Gold et al. 2002; Kawachi and Kennedy 1997). Wilkinson and various other authors have made strong statements in favour of the IIH (Kawachi and Kennedy 1999; Wilkinson and Pickett 2006, 2009). Other authors are not as convinced by this relationship (e.g., Präg et al. 2014; Qi 2012; Zagorski et al. 2014). One possible reason for this controversy is that the relationship has been investigated with a wide variety of methods, which may allow for different results and answers.

This study focuses on moving the literature forward by focusing specifically on empirical rigor. We compare three common methods used to test the IIH. First, we use OLS regression to compare levels of income inequality and health across countries (e.g., Gold et al. 2002; Kawachi and Kennedy 1997; Wilkinson and Pickett 2007). Second, we use multilevel models to compare the health of individual citizens across countries, while controlling for individual-level factors and modelling individuals not as independent observations but as observations nested within countries (e.g., Kondo et al. 2009; Layte 2012; Rözer and Volker 2015). Third, fixed effects models are used to compare changes in income inequality within countries (e.g., Pop et al. 2013; Avendano 2012; Babones 2008; Mellor and Milyo 2001). When looking at within-country variation, between-country variation can be ignored, which is likely to be affected by unmeasured country characteristics, such as cultural differences between countries or differences in the interpretation of key questions about health and social trust (Dorling and Barford 2009).

In addition, we propose an alternative method to test the IIH by analysing pseudo panel data. In our case, we analyse subgroups of cohorts. By analysing cohort groups and adding country-level fixed effects, cohorts within countries are tracked over time. This has several advantages. First, pseudo panel data is the best substitute for longitudinal cross-sectional data that can be obtained without actually following individuals. Hence, it moves the focus from macro to micro data, unlike classical fixed effects models. Second, changes often occur over time within countries because cohorts are replaced over time (Mannheim 1952; Rözer and Volker 2015). Thus, changes might not be accounted for by period but rather by cohort effects. Pseudo panel data avoids this problem because cohorts are tracked over time. Third, following cohorts over time enables researchers to control for unmeasured confounders, such as wealth differences or motorization effects that differ across cohorts. Fourth, by making use of subgroups, more information from the original data is used than would be with standard fixed effects models. Thus, with this newly applied method we can even more rigorously test the IIH.

After a series of papers of Verbeek (Verbeek and Vella 2005; Verbeek 2007), pseudo panels have become increasingly popular in economic oriented studies over the last years. For example, it has been used to examine the preferences for redistribution (Olivera 2012), the vulnerability for poverty (Échevin 2013), price elasticities of alcohol demand (Meng et al. 2014), and to study poverty dynamics (Dang and Lanjouw 2013). However, as far as we know, this type of analyses has not yet been conducted in articles that test the IIH (nor in sociological journals in general). 
Thus, OLS, multilevel, country fixed effects and fixed effects models with pseudo panel data were compared to determine the extent to which income inequality affects health. The measures of health that we considered were self-rated health, mortality rate and life expectancy.

\section{The Income Inequality Hypothesis}

Advocates of the income inequality hypothesis (IIH) have argued that income inequality has a direct effect on health by affecting people's psychosocial well-being. In addition, social trust is thought to mediate the association between income inequality and health. In this section, we elaborate briefly on these arguments.

The most common explanation for the effect of income inequality on health is the psychosocial argument, which suggests that, as a result of income inequality, psychosocial stress rises, which reduces the state of health in society (e.g., Kawachi et al. 1997; Layte and Whelan 2014; Lynch et al. 2014; Subramanian and Kawachi 2004; Whelan and Maître 2013). Unequal societies show greater differences between individuals, which produces higher levels of competition. Higher levels of competition are thought to increase frustration and stress among people within the population. This affects all people in society because the competition flows through all strata (Wilkinson 1996). Individuals may try to cope with stress by seeking rewards from other sources as they become more susceptible to unhealthy food or addictions, which results in more health related problems (Rözer and Kraaykamp 2012).

Social trust is expected to be one of the most important mediators of the relationship between income inequality and health (e.g., Kawachi and Kennedy 1997; Delhey and Dragolov 2013; Layte 2012; Rözer et al. 2016). Generally, social trust can be described as the state that exists between individuals where rational consideration is no longer possible (Lewis and Weigert 1985). Social trust makes people dare to step outside their own world, which enhances their interest in other people in general. This may lead to mutual understanding, feelings of solidarity and, consequently, philanthropic behaviour (Rothstein and Uslaner 2005). Therefore, it is regarded as one of the most important aspects of social capital, regardless of whether it is a property of individuals (e.g., Coleman 1988) or nations (e.g., Putnam 2001).

Income inequality can decrease social trust because it creates dissimilarities between people, which can lead to a society becoming more heterogeneous. Because people are more inclined to trust those who are similar to them, the 'aversion to heterogeneity' principle states that, when there is greater heterogeneity in society, people will trust others less (Zak and Knack 2001). Furthermore, the 'social success and well-being' theory explains that, in more unequal countries, there are more poor people who are inclined to trust others less. This is because they are, by necessity, more prone to take risks (Delhey and Newton 2003). Hence, poor people will be more inclined to seek certainty, and trust is, of course, never certain (Kahneman and Tversky 1979). In addition, when individuals are surrounded by non-trusting people, they may become less inclined to help others (Alesina and La Ferrara 2002). In this way, low trust may spread across society.

High levels of social trust are associated with better individual health (e.g., Jen et al. 2010). At the individual level, trust may create a social context or environment that is more peaceful and less stressful (Takahashi et al. 2005). In addition, social trust increases reciprocity and can therefore be an important resource and thus a form of social capital, 
which might help people live healthier (Coleman 1988). At a societal level, social trust facilitates cooperation by providing a safer social context (Kawachi and Kennedy 1999). In a society with high social trust, there will be more obligations and expectations that will be met. For instance, this may translate into social support and 'diffusion of innovations' (Kawachi and Kennedy 1999). This suggests that innovative behaviour (e.g., information channels or preventive services) diffuses much more rapidly in communities that are cohesive and in which members know and trust one another.

The compositional and policy arguments are well-known alternative explanations for inequality effects. These should be mentioned, but they can be regarded as not directly explaining the effect of income inequality on health. According to the composition argument, income inequality logically implies that there are more poor people (in absolute terms) in societies, who have relatively poor health. Thus, the overall standards of health within a country with high inequality will be low. In addition, the poor might influence other people with unhealthy lifestyles, crime or other activities that are associated with having a low income (Kawachi and Kennedy 1997). According to the policy argument, unequal societies are associated with underinvestment in social policies and processes, which may result in lower overall health (Coburn 2000; Veenstra 2002; Subramanian and Kawachi 2004). In our analyses, we control for these two arguments.

\section{Data, Measurements and Methods}

\subsection{Data Collection}

To test our model, we combined data from the World Values Survey (WVS) and the European Values Study (EVS) (WVS 1981-2008; EVS 2011; WVS 2014). These datasets consist of national cross-sectional data collected over time, and they provide information on health, social trust and several other characteristics at the individual level. The surveys were designed to gather information from a representative random sample of the adult population within each country. However, the exact method of gathering the data was not standardized, so the samples were not always random and representative. For example, sampling techniques differ between countries, such that non-response varies considerably (from 25 to 95 percent) and can sometimes not be calculated because quota sampling is applied. Although there is a slight oversampling of Western countries, all continents are well represented. The third wave of the EVS did not include questions on individual health and is therefore excluded from the analysis. This dataset contains data from 1980 up until 2014 and information on 80 countries (see Supplementary Table). The size of the dataset is particularly important in this study because the key variables change little over time. Using smaller samples would lead to reduced variance over time, which would make it especially hard to estimate the effects in fixed effects models.

\subsection{Measurements}

\subsubsection{Dependent Variable}

Individual health was measured as self-rated health. Self-rated health has been the most frequently used measure of health in previous research (Kondo et al. 2009). It is measured using the following question: "All in all, how would you describe your state of health these 


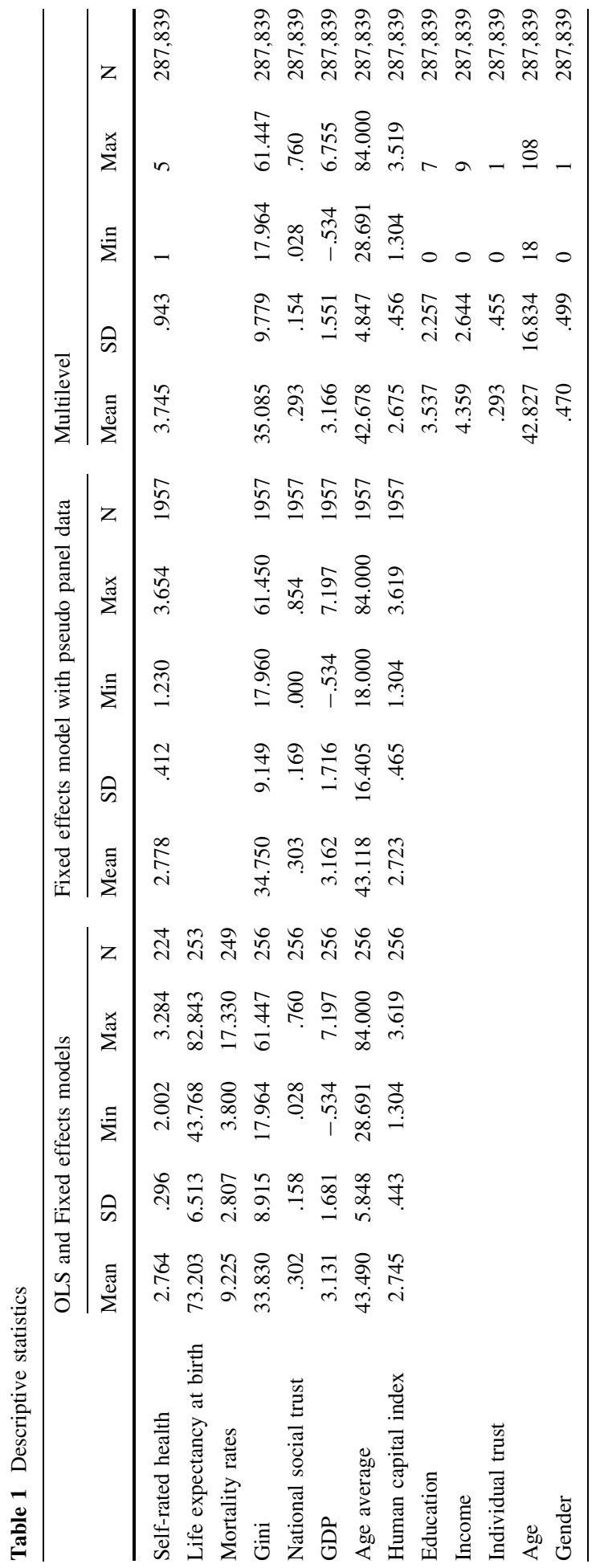


days?" The respondents choose from 'very poor' (1), 'poor' (2), 'fair' (3), 'good' (4) and 'very good' (5). Self-rated health as a measurement of health has been tested in previous studies on retest reliability and compared with other measurements of health, such as mortality rate (Clarke and Ryan 2006; Lundberg and Manderbacka 1996). The results of these studies indicate that self-rated health is a reliable measurement of health.

In addition to individual measurements of health, national characteristics of health were considered. The World Bank provides information on crude death rates (i.e., mortality rates) and life expectancy at birth. In previous research, these measurements of health have often been used to test the IIH because of their availability and generalizability (e.g., Judge 1995; Kawachi et al. 1997), which make them interesting as complements to self-rated health. ${ }^{1}$

\subsubsection{Independent Variables}

Data on income inequality were obtained from the Standardized World Income Inequality Database (SWIID) (Solt 2009). This dataset provides comparable Gini coefficients for the largest possible sample of countries and years available. It provides us with Gini index data that were initially measured with several different methods and standardized for use in national comparisons, reducing many of the problems with previous data used in comparative studies (United Nations University (UNU)-WIDER 2008).

The concept of social trust is measured with the same widely used standard question in the EVS and WVS (e.g., Delhey and Dragolov 2013; Layte 2012; Rözer and Kraaykamp 2012). "Generally speaking, would you say that most people can be trusted or that you can't be too careful in dealing with people?" The respondents chose from two answers: "you cannot be too careful" (0) and "most people can be trusted" (1).

\subsubsection{Control Variables}

National characteristics of wealth were used to control for absolute income effects at the national level. Measures of Gross Domestic Product (GDP) per capita were taken from the extensive Penn's World Trade Tables (Feenstra et al. 2013). The logarithm of GDP was used in the analyses because wealth becomes less important for health as wealth increases. Secondly, the human capital index from the Penn's World Trade Tables was included to account for the expected association between a country's stock of human capital and its income inequality. The stock of human capital in a country is clearly related to the health of its citizens. Additionally, age was aggregated as the mean age of a country wave for the aggregated analyses in order to control for important demographic differences between countries (and cohorts), which may affect people's health.

In the multilevel analysis, several individual level variables were used as control variables. The first individual level control variable was relative perceived income. Respondents were asked to grade their income position in their country by asking the following question: 'On this card is an income scale on which 1 indicates the lowest income group and 10 the highest income group in your country. We would like to know in what group your household is. Please, specify the appropriate number, counting all wages, salaries, pensions and other incomes that come in.' Answer categories were rescaled,

\footnotetext{
1 The correlation between the measures varies from moderate to weak; i.e. self-rated health with mortality rates $(\mathrm{r}=-.427)$, self-rated health with life expectancy $(\mathrm{r}=.248)$, and mortality rates with life expectancy $(\mathrm{r}=-.351)$.
} 
ranging from (0) 'lowest group' to (9) 'highest group'. Second, the level of education was measured as the highest educational level achieved, ranging from (0) primary education not finished, to (7) finished university. When other information was available, because respondents were asked about their education in years instead of in categories, the missing values for the highest educational level achieved were replaced by using education scores measured in years. ${ }^{2}$ Furthermore, age, gender, marital status, employment status and religious denomination are also used as control variables. Multiple imputation was used to fill in the missing values for these individual level variables. There was a particularly large proportion of missing values for income $(21.9 \%)$.

\subsection{Analytical Strategy}

In line with previous research, we applied three often-used statistical methods to study the IIH: OLS, multilevel and fixed effects regression. These methods allowed us to determine the extent to which previous outcomes were affected by their choice of method. In addition, to build upon the standard fixed effects models, we used fixed effects models with pseudo panel data.

First, as a base model, OLS regressions were conducted on aggregated data at the country wave level. In the OLS and fixed effects model, the variables drawn from the EVS and WVS (i.e., age, self-rated health and social trust) were aggregated by taking the mean score for each country wave before the analysis. OLS regression can be used to determine whether there is an association between country-level health and income inequality. The well-known OLS model can be represented as follows:

$$
Y_{j}=\beta_{0}+\beta_{1} X_{j}+\varepsilon_{j}
$$

The subscript $j$ indicates countries, $Y_{j}$ denotes the outcome, $\beta_{0}$ represents the intercept, and $X_{j}$ stands for the covariates income inequality and social trust, and the control variables. Among the control variables, dummy variables were added to control for effects across time, which can also be regarded as fixed effects.

Secondly, multilevel regressions, or random effects models, are used (Hox 2010). In these models, information was based on the individual (i) and country (j) levels. An extra error term $\left(\mu_{j}\right)$ separated the components of sampling variability attributable to individuallevel and country-level effects, and the term accounted for the possibility that observations within countries may be correlated. This avoided violating the assumption of independence of observations, and correspondingly assured that standard errors were correctly estimated. The extent to which individuals belonging to the same country resemble one another can be expressed by the intra-class correlation, which is the proportion of individual-level variance out of the total variance $\left(\rho=\varepsilon_{i j} /\left(\mu_{j}+\varepsilon_{i j}\right)\right)$. Using country fixed effects to control for individuals being nested within countries is of course possible, but it implies that national level variables, like the Gini, cannot be added to the model. Only self-rated health was used as a dependent variable because this is the only dependent variable that was measured on the individual-level. Multilevel regression allows the researcher to study whether differences in income inequality at the country-level are related to health outcomes at the individual-level. The model is expressed as follows:

\footnotetext{
${ }^{2}$ Repeated single imputation in which education in years and our other variables (e.g. income, age, gender) were used to impute the missing values for the highest educational level achieved. The high correlation between education in terms of categories and years $(r=.931)$ justifies this approach and simplifies further analyses.
} 


$$
Y_{i j}=\beta_{0}+\beta_{1} X_{i j}+\beta_{2} X_{j}+\mu_{j}+\varepsilon_{i j}
$$

Here, $X_{i j}$ represents individual-level covariates, and $X_{j}$ represents country-level covariates, $\beta_{0}$ denotes the intercept, $\mu_{j}$ is the error term for the country-level, and $\varepsilon_{i j}$ is the error term for the individual level. Again, dummy variables were used to simplify the model and to capture the effects of unmeasured time effects that vary across waves but not across countries and individuals in the same wave.

Third, fixed effects models were estimated. Data were again aggregated at the countrylevel. In the fixed effects models, time series were nested within countries. As a result, only within-country variance was analysed. Additionally, time fixed effects were used to model time-specific effects that did not vary across countries. By using country fixed effects $\left(\beta_{0 j}\right)$, we examined changes within countries and were able to control for country-level unobserved heterogeneity. Estimators of fixed effects models are, thus, not contaminated with spurious effects of stable, unmeasured country characteristics (Verbeek 2004). ${ }^{3}$ Effects that vary across time are still controlled by using dummy variables. These represent the average change in health across time. Fixed effects models can be used to determine whether changes within countries, with respect to levels of income inequality, are related to changes in health at the country-level:

$$
Y_{j t}=\beta_{0 j}+\beta_{1} X_{j t}+\varepsilon_{j t}
$$

Finally, pseudo panel datasets were created so that subgroups instead of populations become the unit of analysis (Deaton 1985; Moffitt 1993; Verbeek and Vella 2005; Verbeek 2007). We analysed subgroups of cohorts (c), but analysing other time-invariant subgroups is also possible (e.g., race or gender). By adding country $\left(\beta_{0 j}\right)$ and cohort $\left(\beta_{0 c}\right)$ fixed effects, we followed cohorts over time. ${ }^{4,5}$ We followed procedures used in previous studies (e.g., Meng et al. 2014) and divided the cohort groups into timeslots of 5 years. The first and the last cohorts included outliers on both ends. Periods of 5 years were used to ensure sufficient variety across cohorts at the levels of income inequality and health, and to allow the cohort averages to be based on sufficient sample sizes. Smaller and somewhat larger cohorts did not alter our results. As self-rated health was our only variable that varied across individuals and cohorts, it was the only dependent variable used for the multilevel and the cohort fixed effects models. The model can be written as follows:

$$
Y_{c j t}=\beta_{0 j}+\beta_{0 c}+\beta_{1} X_{c j t}+\varepsilon_{c j t}
$$

To test for the mediating effect of trust in our models, we employed two strategies. In the multilevel setting, we used Mplus 7.0 with bootstrapping to account for the non-normal distribution of the indirect effect (Preacher and Hayes 2008). Because Mplus and other

\footnotetext{
3 To test whether a fixed or random effects model is appropriate for these data, the Hausman test was conducted (Hausman 1978). The Hausman test indicates that a fixed effects model, rather than a randomeffects model, is most appropriate to examine our data because the assumption of no correlation between the country-specific effects and independent variables was not met: Chi squared $(5)=30.976, \mathrm{p}<.001$.

4 Due to the high cost (in degrees of freedom) of modelling the interaction between country and cohort fixed effects, it was not possible to strictly follow cohorts over time. However, because the average age was used as a control variable, the results would most likely not differ from a more complex model in which cohorts were tracked over time.

5 Although this method does not follow individuals over time, it does not necessarily produce inferior results. Compared to individual data, repeated cross-sections suffer much less from typical panel data problems like attrition and non-response (Verbeek 2007).
} 
structural equation modelling programs have problems mimicking fixed effects models with unbalanced longitudinal datasets (Allison 2009), the Mediation package for R (Tingley et al. 2013) was used to estimate the indirect effects of our OLS and fixed effects models. Again, bootstrapping was performed to test the indirect effect of trust.

\section{Results}

To make the models more comparable, analyses that used self-rated health as the dependent variable were performed with the same data, consisting of 80 countries and 224 country-waves. Table 1 shows the descriptive statistics of the models.

\subsection{OLS Regression}

First, OLS regressions were performed. Table 2 shows that, unexpectedly, income inequality had a positive effect on self-rated health and a negative effect on mortality rate. The effect of income inequality on life expectancy was negative, as expected, indicating that the country with the lowest level of income inequality had a life expectancy 10 years higher than the country with the highest level of income inequality. Social trust was associated with better health for all health measures, and it significantly mediated income inequality in all three models. GDP was positively associated with mortality rate and life expectancy. Average age showed a negative effect on self-rated health and mortality rate, but life expectancy showed no significant effects. The human capital index showed a positive association only with life expectancy.

\subsection{Multilevel Model}

Table 3 shows the outcomes of the multilevel models. The intra-class correlation shows that about nine percent of the variance in self-rated health is accounted for by the clustering within countries. This justifies the use of a multilevel approach for this type of data. Again, income inequality was associated with better self-rated health; the country with the highest level of inequality was predicted to have a .215 higher average score for self-rated health compared to the country with the lowest level of inequality. This runs counter to the IIH. On the individual- and country-level, social trust was positively associated with self-rated health, although the effect of country-level social trust was substantially larger $(b=.649$, $p<.001$ and $b=.131, p<.001)$. In addition, income inequality was associated with lower national social trust. Hence, in line with the $\mathrm{IIH}$, the multilevel models suggest that social trust mediates the association between income inequality and health. This effect would not change if, instead of an indirect effect of national social trust, we tested the indirect effect of individual social trust.

Moving towards the control variables, living in a wealthier country, with a higher GDP per capita, was again positively associated with better health. The other country-level control variables were not significant. Our individual-level control variables are not presented in order to make comparisons between models easier (but are available upon request). However, they show well-known effects. Education, being female, and income all show positive effects on self-rated health. The work activity variables all show negative effects compared to individuals with full-time jobs. Married people also have higher scores than all other marital statuses, except for singles, who score equally well. Moreover, the 


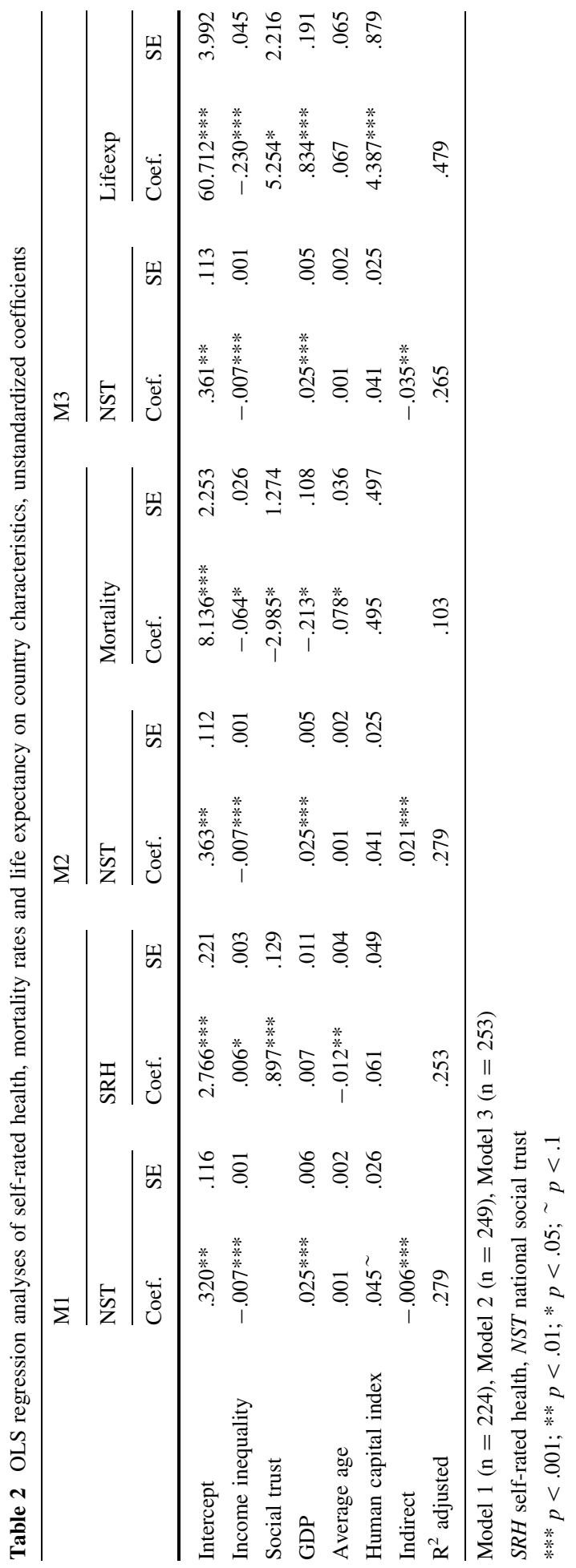


Table 3 Multilevel regression of self-rated health on individual and country characteristics, unstandardized coefficients

Controlling for work status, marital status, denomination and the wave of the survey

Number of cases 287.839 , number of country-waves 224

SRH self-rated health, NST national social trust

$* * * p<.001 ; * * p<.01$; $* p<.05 ; \sim p<.1$

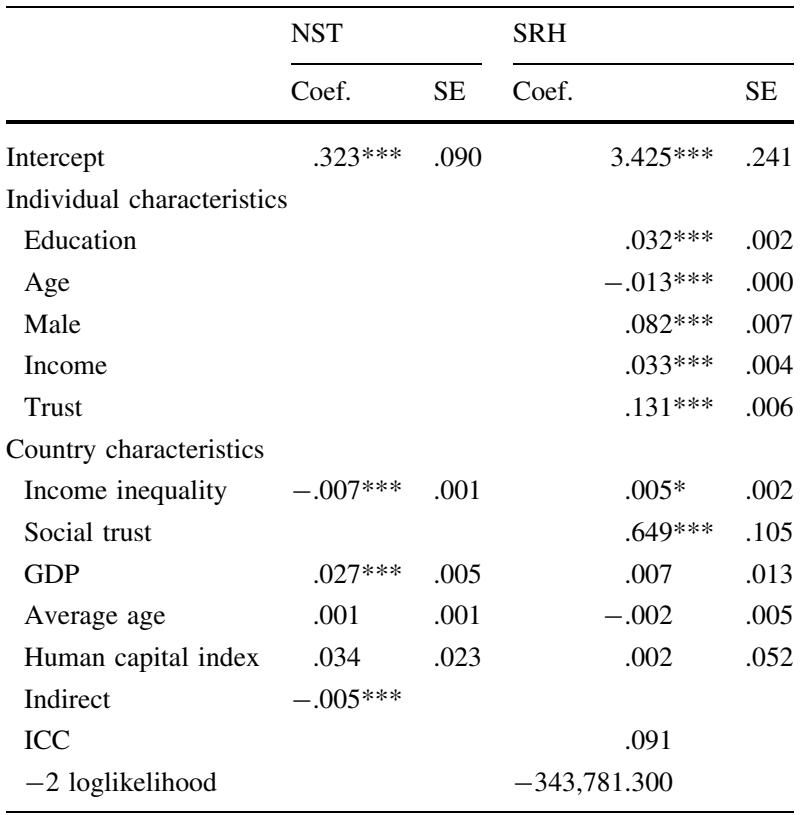

model demonstrates that Protestants and Buddhists score higher on self-rated health than people without religion, whereas Orthodox adherents score lower.

\subsection{Fixed Effects Models}

Table 4 shows the results for fixed effects models. In line with the OLS models, and as the IIH predicts, income inequality is still associated with lower life expectancy. Interestingly, compared to the OLS and multilevel models, the signs of income inequality and self-rated health, and income inequality and mortality, are reversed and in line with the IIH: income inequality is associated with lower self-rated health and higher mortality rates. Hence, it seems that the better we control for between country variance, the more support we find for the IIH. Social trust is still associated with good health (although not significant with respect to life expectancy), and it still mediates the relationship between income inequality and health.

The control variables show more significant associations with our health measures. When we are able to control for between-country variation, associations with health become visible. The effect of average age becomes negatively associated with self-rated health. Thus, older people report poorer health. In addition, human capital becomes positively associated with self-rated health and borderline significantly related with life expectancy. The more countries invest in human capital, for instance through schooling, the more the health of citizens improves. GDP remains negatively associated with health, but this effect is not significant with respect to self-rated health. 


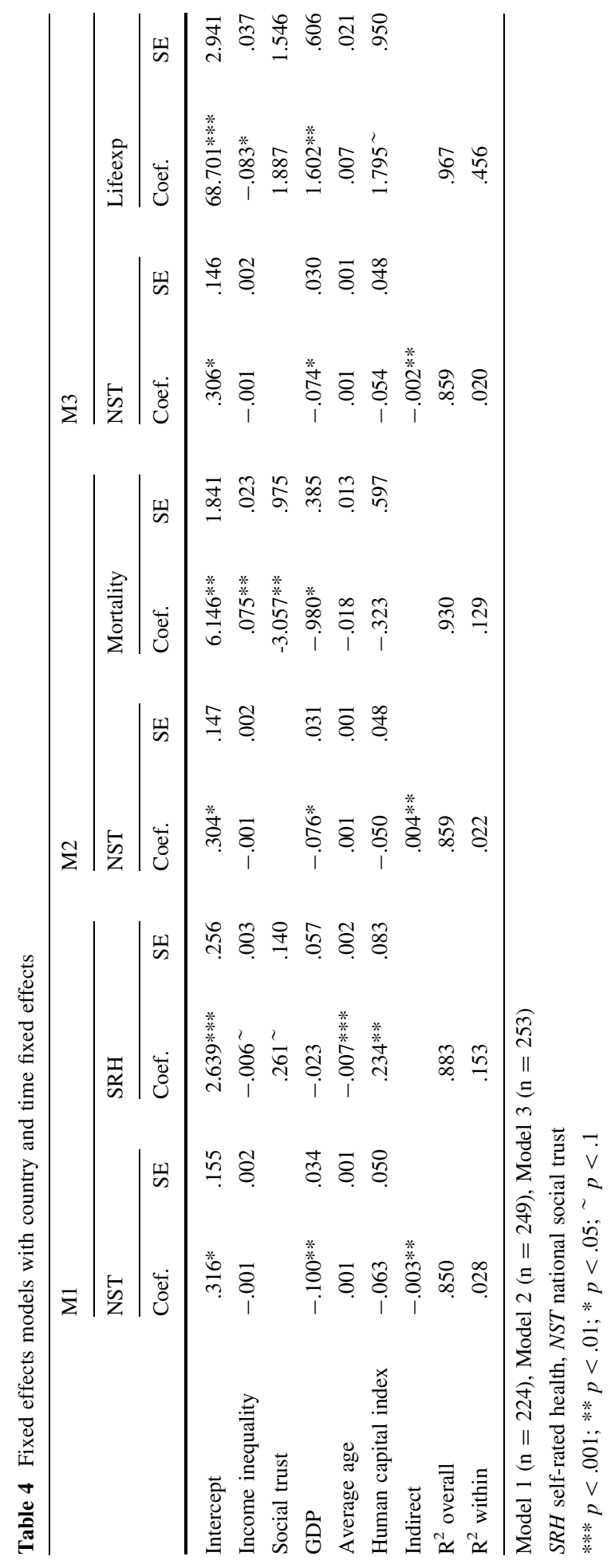


Table 5 Fixed effects models using pseudo panel data with country, time and cohort fixed effects, for selfrated health

\begin{tabular}{|c|c|c|c|c|}
\hline & \multicolumn{2}{|l|}{ NST } & \multicolumn{2}{|l|}{ SRH } \\
\hline & Coef. & SE & Coef. & SE \\
\hline Intercept & $.485^{* * *}$ & .081 & $2.837 * * *$ & .185 \\
\hline Income inequality & -.001 & .001 & $-.005^{* *}$ & .002 \\
\hline Social trust & & & $.374 * * *$ & .052 \\
\hline GDP & $-.117 * * *$ & .013 & -.014 & .031 \\
\hline Average age & $-.002^{*}$ & .001 & $-.015 * * *$ & .002 \\
\hline Human capital index & $-.062 * *$ & .021 & $.243 * * *$ & .047 \\
\hline Indirect & $-.004 * *$ & & & \\
\hline $\mathrm{R}^{2}$ overall & .824 & & .848 & \\
\hline
\end{tabular}

Model $(\mathrm{n}=1.957)$

$S R H$ self-rated health, NST national social trust

$* * * p<.001 ; * * p<.01 ; * p<.05 ; \sim p<.1$

\subsection{Fixed Effects Models with Pseudo Panel Data}

Table 5 shows the results of the fixed effects models applied to the pseudo panel data. When the effect of income inequality on health was positive in the OLS and multilevel models and negative but borderline significant in the fixed effects, it became more negative and significant in the pseudo panel data. Hence, the better we control for between-country variation and the closer we follow groups through society, the more our models support the IIH. Furthermore, social trust still mediates the relationship between income inequality and health, as predicted by the IIH.

The control variables show effects similar to the fixed effects models. The human capital index has a positive effect on self-rated health, and people in older societies report lower health. GDP remains negatively, but not significantly, associated with lower selfrated health.

\subsection{Robustness Checks}

Much of the debate on income inequality focuses on the differences between developed and developing countries. In developed countries, the effects of wealth are expected to be less important; yet, other socio-psychological factors, such as stress induced by income inequality, are expected to be more important (Wilkinson and Pickett 2009). Therefore, separate analyses were conducted using a selection of high income countries only, as indicated by a GNP per capita of $\$ 12,746$ or more (World Bank 2015). The results are summarized in Table 6. In the OLS models, contrary to the IIH, income inequality was associated with lower mortality rates, and no significant effects were found for the other dependent variables. In the fixed effects models, income inequality was associated with higher self-rated health, lower mortality rate and higher life expectancy for high-income 
Table 6 OLS and Fixed effects models on high income countries and non-high income countries separately

\begin{tabular}{|c|c|c|c|c|c|c|c|}
\hline \multirow[t]{2}{*}{ Method/selection/N } & \multirow[t]{2}{*}{ Variable } & \multicolumn{2}{|c|}{$\begin{array}{l}\text { Self-rated } \\
\text { health }\end{array}$} & \multicolumn{2}{|c|}{ Mortality rates } & \multicolumn{2}{|c|}{$\begin{array}{l}\text { Life } \\
\text { expectancy }\end{array}$} \\
\hline & & NST & SRH & NST & Mortality & NST & Lifeexp \\
\hline \multirow{2}{*}{$\begin{array}{l}\text { OLS regression/high income } \\
\text { countries/(N = 136/164/164) }\end{array}$} & Income inequality & - & NS & - & - & - & NS \\
\hline & Social trust & + & & - & & + & \\
\hline \multirow{2}{*}{$\begin{array}{l}\text { OLS regression/non-high income } \\
\text { countries/(N = 92/90/94) }\end{array}$} & Income inequality & - & + & - & NS & - & - \\
\hline & Social trust & NS & & NS & & NS & \\
\hline \multirow{2}{*}{$\begin{array}{l}\text { FE regression/high income } \\
\text { countries/(N = 136/164/164) }\end{array}$} & Income inequality & NS & - & NS & + & NS & - \\
\hline & Social trust & NS & & - & & NS & \\
\hline \multirow{2}{*}{$\begin{array}{l}\text { FE regression/non-high income } \\
\text { countries/(N = 92/90/94) }\end{array}$} & Income inequality & NS & NS & NS & NS & NS & NS \\
\hline & Social trust & + & & NS & & NS & \\
\hline \multirow{2}{*}{$\begin{array}{l}\text { Pseudo panels/high income } \\
\text { countries/(N = 1149) }\end{array}$} & Income inequality & NS & - & & & & \\
\hline & Social trust & + & & & & & \\
\hline \multirow{2}{*}{$\begin{array}{l}\text { Pseudo panels/non-high income } \\
\text { countries/(N = 842) }\end{array}$} & Income inequality & NS & - & & & & \\
\hline & Social trust & + & & & & & \\
\hline
\end{tabular}

SRH self-rated health, NST national social trust, - significant negative effect, + significant positive effect, $N S$ non-significant effect

countries, and no significant effects were found for the non-high-income countries. ${ }^{6}$ Thus, our main results appear to be robust even when tested on different sub-samples of the data.

Additionally, previous studies suggest that the effects of income inequality may be delayed up to 15 years and may account for the etiological period for income inequality to affect health (Blakely et al. 2000; Karlsdotter et al. 2012; Mellor and Milyo 2003). Therefore, lagged effects of income inequality for 5-, 10- and 15-years were tested in the models. However, no notable differences from our main results were observed. Several outliers were identified within the fixed effects models; these showed strong fluctuations within countries across time. Separate analyses were performed without outliers; however, the results did not differ greatly from the initial results. Overall, these findings increase our confidence in our results.

Moreover, as argued in theory, income inequality may affect individual's health through psychosocial and institutional mechanisms. According to the institutional mechanism of health, and, more generally, government expenditures are lower in more unequal countries, which negatively affects health. Therefore, we included health expenditures per capita, from the OECD and WHO, in the models as a proxy for the institutional pathway. As information about health expenditures is not available for all countries considered in our previous analyses, we only used information from 74 countries. Because the effect of income inequality on health does not significantly change when we add health expenditure to the models, we find little evidence for the institutional pathway. This suggests, as the IIH predicts, that income inequality health associations can be attributed to the social-psychological pathway. We note that some unequal countries have notoriously costly but ineffective health care systems, particularly, the United States. However, excluding the United States did not alter our results.

\footnotetext{
${ }^{6}$ Similar differences in previous results occurred when using mainly communistic or European countries (Jen, Jones, and Johnston 2009). Selecting these countries produced stronger significant results than their counterparts, but the results were in line with our conclusions.
} 
Furthermore, differences between the results and the predictions of the IIH may be caused by the use of different measurements and datasets across studies. Therefore, the models were replicated with European Social Survey (ESS) data, consisting of 114 country waves and 1140 pseudo panel observations. The ESS includes fewer countries than the WVS/EVS, but it has the advantage of measuring trust on a ten-point scale instead of as the binary question used in the WVS/EVS. Overall, quite similar results were found, although the effect of social trust was stronger, as could be expected with a more refined measurement.

Additionally, separate analysis with the EVS and WVS or with a dichotomous measure of self-rated health were performed. These showed very similar results to the previous analyses. Finally, estimating the multilevel data, in which individuals were nested within countries, with clustering correction and time fixed effects, yields very similar results as our multilevel models. ${ }^{7}$

\section{Conclusion and Discussion}

The consequence of income inequality on individual health is still a strongly debated topic in the academic world. The main advantage of this study is its use of four different statistical methods to test the income inequality hypothesis (IIH). The methods used were OLS regression, multilevel models, fixed effects models and fixed effects models with pseudo panel data. The latter, being the first time used to test the IIH, provides yet another rigorous measure to test it.

As expected based on the literature (e.g., Kondo et al. 2009; Pickett and Wilkinson 2015), mixed effects were found for the relationship between income inequality and health. Around half of our results are in favour of the IIH. However, there are interesting differences between the models. They suggest that part of the evidence against the IIH can be attributed to confounding variables because the fixed effects and pseudo panel data, which can be used to control most rigorously for these confounding variables by looking at within country variance, show support for the IIH. Thus, the better we control for unobserved variables and biases, the more support we find for the IIH. Biases that might hamper OLS and multilevel studies include the different perceptions of self-rated health across countries and cultural/historical differences between countries (e.g., Dorling and Barford 2009; Pickett and Wilkinson 2015; Wilkinson and Pickett 2006).

Additionally, compared to the fixed effects models, the pseudo panel models show stronger significant effects, and they show support for the $\mathrm{IIH}$, which could simply be a result of greater power. However, it might also indicate that the role of cohorts is crucial for understanding the IIH because pseudo panel data follow cohorts over time and avoid the data distortions that occur when cohorts are replaced. It may be that only certain (younger) cohorts are affected by income inequality and that society-wide effects are only notable when cohorts are replaced (Rözer and Volker 2015). Fixed effects models could not have detected this effect, which, in our opinion, demonstrates the strength of the pseudo panel data and illustrates a new method for further theoretical testing of the hypothesis.

In line with the IIH, support was found for the harmful effect of income inequality on health because it reduces social trust (e.g., Kawachi et al. 1997). In our models, income

\footnotetext{
${ }^{7}$ In our application, the difference between the models is that multilevel models, instead of using a clustering correction, explicitly model the dependency in the data and therefore result in more accurate predictions than (most) clustering corrections (Hox 2010: 4).
} 
inequality was associated with lower trust, except in the fixed effects models. Furthermore, social trust was consistently related to higher health, except for life expectancy in the fixed effects model. In all models, we found support for the mediating role of social trust. Additionally, when comparing the effect sizes of the direct effect of income inequality on individual health and the indirect effect mediated by social trust, we found that the effects of income inequality on social trust and of social trust on health were stronger than the direct effect of income inequality on health, emphasising the importance of the indirect pathway.

Our study has some drawbacks that may be addressed in future research. First, our analyses rely, as most studies do, solely on the Gini coefficient as a measure for income inequality. A disadvantage of the Gini coefficient is that it is an average measure of inequality; it does not measure where inequality appears. For example, a country with a small group of very wealthy individuals and a country with a small group of very poor people might have the same Gini coefficient, although the countries clearly differ. Furthermore, income is only one aspect of financial inequality; differences in wealth might be even larger and more important. Furthermore, within our multilevel models, we control for relative, instead of absolute, income, but one of the great strengths of multilevel modelling is that it can control for (absolute) income. Therefore, in contrast to OLS regression, it can distinguish effects of income inequality due to income and compositional differences (Gravelle et al. 2002). Related to this, we control for policy effects by using information about the health expenditures of countries. However, income inequality might be associated with numerous other policy effects, such as low social benefits, which future research may want to control for. Similarly, social trust was only measured with a binary question, which makes it hard to distinguish levels of trust between individuals. As our results using ESS data showed, measuring social trust on a ten-point scale, this might have weakened its effects. In addition, social trust is a broad concept that is associated with a variety of more specific concepts, such as people's openness to others, as well as their social network and social capital. Future research may seek to further disentangle why social trust is important in the association between income inequality and health.

Overall, half of our main results and robustness checks are in contrast with the prevailing hypothesis. However, as with the fixed effects and pseudo panel models, the unexpected results might be explained by unobserved confounders. Thus, if models are better able to control for these confounders, we may find that the income inequality hypothesis is supported. Moreover, as the income inequality hypothesis predicts, there is evidence that income inequality is associated with low trust and thus indirectly associated with health. Hence, our results indicate that, as the income inequality hypothesis predicts, income inequality is associated with ill health, but to a large extent this is because income inequality decreases social trust. The strong support that the pseudo panel data provide for these relationships suggests that cohort effects may play an important role in explaining why income inequality can be detrimental to health. Obviously, future research is needed to more fully understand the role of cohorts, but this study shows the usefulness of the newly applied method.

Acknowledgments We are grateful for Beate Völker's, Alexander Grims', and Zoltan Lippenyi's feedback throughout the writing process.

Open Access This article is distributed under the terms of the Creative Commons Attribution 4.0 International License (http://creativecommons.org/licenses/by/4.0/), which permits unrestricted use, distribution, and reproduction in any medium, provided you give appropriate credit to the original author(s) and the source, provide a link to the Creative Commons license, and indicate if changes were made. 


\section{References}

Alesina, A. F., \& La Ferrara, E. L. (2002). Who trusts others? Journal of Public Economics, 85(2), 207-234.

Allison, P. D. (2009). Fixed effects regression models. Los Angeles: Sage.

Avendano, M. (2012). Correlation or causation? Income inequality and infant mortality in fixed effects models in the period 1960-2008 in 34 OECD countries. Social Science and Medicine, 75(4), 754-760.

Babones, S. J. (2008). Income inequality and population health: Correlation and causality. Social Science and Medicine, 66(7), 1614-1626.

Blakely, T. A., Kennedy, B. P., Glass, R., \& Kawachi, I. (2000). What is the lag time between income inequality and health status? Journal of Epidemiology and Community Health, 54(4), 318-319.

Clarke, P. M., \& Ryan, C. (2006). Self-reported health: Reliability and consequences for health inequality measurement. Health Economics, 15(6), 645-652.

Coburn, D. (2000). Income inequality, social cohesion and the health status of populations: The role of neoliberalism. Social Science and Medicine, 51, 135-146.

Coleman, J. S. (1988). Social capital in the creation of human capital. American journal of sociology, 94, 95-120.

Dang, H. A., \& Lanjouw, P. (2013). Measuring poverty dynamics with synthetic panels based on crosssections. World Bank Policy Research Working Paper No. 6504. Washington DC: The World Bank.

Deaton, A. (1985). Panel data from time series of cross-sections. Journal of Econometrics, 30(1-2), $109-126$.

Delhey, J., \& Dragolov, G. (2013). Why inequality makes Europeans less happy: The role of distrust, status anxiety, and perceived conflict. European Sociological Review, 30(2), 151-165.

Delhey, J., \& Newton, K. (2003). Who trusts?: The origins of social trust in seven societies. European Societies, 5(2), 93-137.

Dorling, D., \& Barford, A. (2009). The inequality hypothesis. Thesis, antithesis, and a synthesis? Health and Place, 15(4), 1166-1169.

Échevin, D. (2013). Measuring vulnerability to asset-poverty in sub-Saharan Africa. World Development, $46,211-222$.

Elgar, F. J. (2010). Income inequality, trust, and population health in 33 countries. American Journal of Public Health, 100(11), 2311-2315.

EVS. (2011). European values study 1981-2008, longitudinal data file. GESIS Data Archive, Cologne, Germany, ZA4804 Data File Version 2.0.0.

Feenstra, R. C., Inklaar, R., \& Timmer, M. P. (2013). The next generation of the Penn World Table. www. ggdc.net/pwt.

Gold, R., Kennedy, B., Connell, F., \& Kawachi, I. (2002). Teen births, income inequality, and social capital: Developing an understanding of the causal pathway. Health and Place, 8(2), 77-83.

Gravelle, H., Wildman, J., \& Sutton, M. (2002). Income, income inequality and health: What can we learn from aggregate data? Social Science and Medicine, 54(4), 577-589.

Hausman, J. A. (1978). Specification tests in econometrics. Econometrica, 46(6), 1251-1271.

Hox, J. J. (2010). Multilevel analysis: Techniques and applications (2nd ed.). London: Psychology Press.

Jen, M. H., Jones, K., \& Johnston, R. (2009). Global variations in health: Evaluating Wilkinson's income inequality hypothesis using the World Values Survey. Social Science and Medicine, 68(4), 643-653.

Jen, M. H., Sund, E. R., Johnston, R., \& Jones, K. (2010). Trustful societies, trustful individuals, and health: An analysis of self-rated health and social trust using the World Value Survey. Health \& Place, 16(5), $1022-1029$.

Judge, K. (1995). Income distribution and life expectancy: A critical appraisal. British Medical Journal, 311, 1282-1285.

Kahneman, D., \& Tversky, A. (1979). Prospect theory: An analysis of decision under risk. Econometrica, 47(2), 263.

Karlsdotter, K., Martín, J. J. M., \& del Amo González, M. P. L. (2012). Multilevel analysis of income, income inequalities and health in Spain. Social Science and Medicine, 74(7), 1099-1106.

Kawachi, I., \& Kennedy, B. P. (1997). Socioeconomic determinants of health: Health and social cohesion: Why care about income inequality? British Medical Journal, 314(7086), 1037.

Kawachi, I., \& Kennedy, B. P. (1999). Income inequality and health: Pathways and mechanisms. Health Services Research, 34(1), 215-227.

Kawachi, I., Kennedy, B. P., Lochner, K., \& Prothrow-Stith, D. (1997). Social capital, income inequality, and mortality. American Journal of Public Health, 87(9), 1491-1498.

Kondo, N., Sembajwe, G., Kawachi, I., Van Dam, R. M., Subramanian, S. V., \& Yamagata, Z. (2009). Income inequality, mortality, and self rated health: Meta-analysis of multilevel studies. British Medical Journal, 339, 4471. 
Layte, R. (2012). The association between income inequality and mental health: Testing status anxiety, social capital, and neo-materialist explanations. European Sociological Review, 28(4), 498-511.

Layte, R., \& Whelan, C. T. (2014). Who feels inferior? A test of the status anxiety hypothesis of social inequalities in health. European Sociological Review, 30(4), 525-535.

Lewis, J. D., \& Weigert, A. (1985). Trust as a social reality. Social Forces, 63(4), 967-985.

Lundberg, O., \& Manderbacka, K. (1996). Assessing reliability of a measure of self-rated health. Scandinavian Journal of Public Health, 24(3), 218-224.

Lynch, J., Smith, G. D., Harper, S., Hillemeier, M., Ross, N., Kaplan, G. A., \& Wolfson, M. (2004). Is income inequality a determinant of population Health? Part 1. A systematic review. Milbank Quarterly, 82(1), 5-99.

Mannheim, K. (1952). Das problem der generations (the problems of generations). In P. Kecsemeti (Ed.), Essays on the sociology of knowledge by Karl Mannheim. New York: Routledge and Kegan Paul.

Mellor, J. M., \& Milyo, J. (2001). Reexamining the evidence of an ecological association between income inequality and health. Journal of Health Politics, Policy and Law, 26(3), 487-522.

Mellor, J. M., \& Milyo, J. (2003). Is exposure to income inequality a public health concern? Lagged effects of income inequality on individual and population health. Health Services Research, 38(11), 137-151.

Meng, Y., Brennan, A., Purshouse, R., Hill-McManus, D., Angus, C., Holmes, J., \& Meier, P. S. (2014). Estimation of own and cross price elasticities of alcohol demand in the UK-A pseudo-panel approach using the living costs and food survey 2001-2009. Journal of Health Economics, 34, 96-103.

Moffitt, R. (1993). Identification and estimation of dynamic models with a time series of repeated crosssections. Journal of Econometrics, 59, 99-123.

Olivera, J. (2012). Preferences for redistribution in Europe. IZA Journal of European Labor Studies, 4(1), $1-18$.

Pickett, K., \& Wilkinson, R. G. (2015). Income inequality and health: A causal review. Social Science and Medicine, 128, 316-326.

Pop, I. A., van Ingen, E., \& van Oorschot, W. (2013). Inequality, wealth and health: Is decreasing income inequality the key to create healthier societies? Social Indicators Research, 113(3), 1025-1043.

Präg, P., Mills, M., \& Wittek, R. (2014). Income and income inequality as social determinants of health: Do social comparisons play a role? European Sociological Review, 30(2), 218-229.

Preacher, K. J., \& Hayes, A. F. (2008). Asymptotic and resampling strategies for assessing and comparing indirect effects in multiple mediator models. Behavior Research Methods, 40(3), 879-891.

Putnam, R. D. (2001). Bowling alone: The collapse and revival of American community. New York: Simon and Schuster.

Qi, Y. (2012). The impact of income inequality on self-rated general health: Evidence from a cross-national study. Research in Social Stratification and Mobility, 30(4), 451-471.

Rothstein, B., \& Uslaner, E. M. (2005). All for all: Equality, corruption, and social trust. World Politics, $58(1), 41-72$.

Rözer, J., \& Kraaykamp, G. (2012). Income inequality and subjective well-being: A cross-national study on the conditional effects of individual and national characteristics. Social Indicators Research, 113(3), 1009-1023.

Rözer, J., Kraaykamp, G., \& Huijts, T. (2016). National income inequality and self-rated health. The differing impact of individual social trust across 89 countries. European Societies. doi:10.1080/ 14616696.2016.1153697.

Rözer, J., \& Volker, B. (2015). Does income inequality have lasting effects on health and trust? Social Science and Medicine. doi:10.1016/j.socscimed.2015.11.047.

Solt, F. (2009). Standardizing the world income inequality database. Social Science Quarterly, 90(2), $231-242$.

Subramanian, S. V., \& Kawachi, I. (2004). Income inequality and health: What have we learned so far? Epidemiologic Reviews, 26(1), 78-91.

Takahashi, T., Ikeda, K., Ishikawa, M., Kitamura, N., Tsukasaki, T., Nakama, D., \& Kameda, T. (2005). Interpersonal trust and social stress-induced cortisol elevation. NeuroReport, 16(2), 197-199.

Tingley, D., Yamamoto, T., Keele, L., \& Imai, K. (2013). Mediation: R package for causal mediation analysis. R package version 4.2.3. http://CRAN.R-project.org/package=mediation.

United Nations University (UNU)-WIDER. (2008). World income inequality database, version 2.0c.

Veenstra, G. (2002). Social capital and health (plus wealth, income inequality and regional health governance). Social Science and Medicine, 54(6), 849-868.

Verbeek, M. (2004). A guide to modern econometrics (2nd ed.). Chichester: Wiley.

Verbeek, M. (2007). Pseudo-panels and repeated cross-sections. In L. Mátyás \& P. Sevestre (Eds.), the econometrics of panel data (Vol. 46, pp. 369-383). Berlin: Springer. 
Verbeek, M., \& Vella, F. (2005). Estimating dynamic models from repeated cross-sections. Journal of Econometrics, 127(1), 83-102.

Whelan, C. T., \& Maître, B. (2013). Material deprivation, economic stress, and reference groups in Europe: An analysis of EU-SILC 2009. European Sociological Review, 29(6), 1162-1174.

Wilkinson, R. G. (1996). Unhealthy societies: The afflictions of inequality. London: Routledge.

Wilkinson, R. G., \& Pickett, K. E. (2006). Income inequality and population health: A review and explanation of the evidence. Social Science and Medicine, 62(7), 1768-1784.

Wilkinson, R. G., \& Pickett, K. E. (2007). The problems of relative deprivation: Why some societies do better than others. Social Science and Medicine, 65(9), 1965-1978.

Wilkinson, R. G., \& Pickett, K. E. (2009). The spirit level: Why equality is better for everyone. London: Pinguin books.

World Bank. (2015). World Bank list of economies. Retrieved from http://data.worldbank.org/about/countryand-lending-groups\#High_income.

WVS. (1981-2008). World value survey official aggregate v.20090901, 2009. World Value Survey Association. www.worldvaluesurvey.org. Aggregate File Producer: ASEP/JDS, Madrid.

WVS. (2014). World value survey wave 6 2010-2014 official aggregate v.20140429. World Values Survey Association. www.worldvaluessurvey.org.

Zagorski, K., Evans, M. D. R., Kelley, J., \& Piotrowska, K. (2014). Does national income inequality affect individuals' quality of life in Europe? Inequality, happiness, finances, and health. Social Indicators Research, 117(3), 1089-1110.

Zak, P. J., \& Knack, S. (2001). Trust and growth. The Economice Journal, 111(470), 295-321. 